\title{
Photoelectrochemical properties of doped lanthanum orthoferrites
}

\author{
Isabella Natali Sora ${ }^{a, *}$, Francesca Fontana ${ }^{a}$, Rosalba Passalacqua ${ }^{b}$, Claudio Ampelli $^{b}$, \\ Siglinda Perathoner ${ }^{\mathrm{b}}$, Gabriele Centi ${ }^{\mathrm{b}}$, Francesco Parrino ${ }^{\mathrm{c}}$, Leonardo Palmisano ${ }^{\mathrm{c}}$ \\ a INSTM R.U. Bergamo and Dipartimento di Ingegneria, University of Bergamo, viale Marconi 5, Dalmine, BG I-24044, Italy \\ ${ }^{\mathrm{b}}$ INSTM/CASPE R.U. and Dipartimento di Ingegneria Elettronica, Chimica ed Ingegneria Industriale (DIECII), University of Messina, \\ viale F. Stagno d'Alcontres 31, ME I-98166, Italy \\ c "Schiavello-Grillone" Photocatalysis Group, Dipartimento di Energia, Ingegneria dell'Informazione e Modelli Matematici (DEIM), University of Palermo, \\ Viale delle Scienze, 90128 Palermo, Italy
}

\section{A R T I C L E I N F O}

\section{Article history:}

Received 9 April 2013

Received in revised form 15 July 2013

Accepted 15 July 2013

Available online 31 July 2013

This paper is dedicated to professor Tullio Caronna for his retirement.

\section{Keywords:}

Photocatalysts

Photocurrent response

Quasi-Fermi level

Ferrites

\begin{abstract}
A B S T R A C T
$\mathrm{LaFeO}_{3}$ powders doped with $\mathrm{Sr}(20 \mathrm{~mol} \%)$ and $\mathrm{Cu}(0-10-20 \mathrm{~mol} \%)$ were prepared by citrate autocombustion synthesis and investigated in terms of crystal structure, morphology, surface area and optical properties. All powders showed photocurrent response in the form of a pasted and annealed electrode and as slurry electrode; the highest value was obtained for undoped orthoferrite calcined at $600^{\circ} \mathrm{C}$. Their physical-chemical properties were related to photoelectrochemical behaviour. The position of the quasi-Fermi level of electrons for all the photocatalysts calcined in the range $600-980^{\circ} \mathrm{C}$ is about the same within experimental error (between -0.62 and $-0.67 \mathrm{~V}$ with respect to $\mathrm{Ag} / \mathrm{AgCl}$ reference electrode, at $\mathrm{pH}$ 7). Doping with $20 \mathrm{~mol} \%$ of strontium did not influence the flat band potential of the powders, while doping with copper caused an important and reproducible change in the titration curve, indicating the presence of intermediate energy states in the samples calcined at $600^{\circ} \mathrm{C}$, but not in those calcined at $980^{\circ} \mathrm{C}$.
\end{abstract}

(c) 2013 Elsevier Ltd. All rights reserved.

\section{Introduction}

Recently, perovskite-type transition metal oxides (TMOs) have been proposed as promising photocatalysts for wastewater and air pollution treatments [1-5]. Some perovskite-type TMOs are semiconductors with a band gap narrow enough for efficient absorption of visible light, and thus can potentially be employed as visible-light-active photocatalysts. In this case they offer a strong advantage over the most used photocatalyst for environmental remediation, i.e. titanium dioxide, which absorbs UV light, the use of solar radiation or visible-light lamps, and hence the development of lower costs technologies.

Lanthanum orthoferrite $\mathrm{LaFeO}_{3}$, with perovskite structure, exhibits $p$-type conductivity at high oxygen partial pressures $\left(p_{\mathrm{O} 2}>10^{-4} \mathrm{~atm}\right)$ [6]. $\mathrm{LaFeO}_{3}$ is a charge-transfer-type insulator and exhibits a band-gap energy of about $2.1-2.0 \mathrm{eV}$ [7,8]. Generally, the functional properties of perovskite materials can be controlled either by modulating structure and defectivity or by substitution of the metal in the oxide. On substituting $\mathrm{Sr}^{2+}$ for $\mathrm{La}^{3+}$, hole states with $p$ character are introduced in the system above the Fermi level [8],

\footnotetext{
* Corresponding author. Tel.: +39 035 2052012; fax: +39 0352052310.

E-mail address: isabella.natali-sora@unibg.it (I. Natali Sora).
}

and a band-gap energy at the Fermi level is present for all compositions in the range $0<x<0.67$ as shown by the photoemission study reported in Ref. [9]. While most of the photoelectrochemical properties of strontium-doped $\mathrm{LaFeO}_{3}$ are understood, less is known about the effects of simultaneous substitution of iron with copper.

Copper-doped $\mathrm{LaFeO}_{3}$ is a viable candidate as visible-light photocatalytic material, however most of the technical requirements (large specific surface area, high photocatalytic activity, chemical stability, structural integrity, etc.) have not been sufficiently investigated. As a part of an ongoing study on $\left(\mathrm{La}_{1-x} \mathrm{~A}_{x}\right)\left(\mathrm{Fe}_{1-y} \mathrm{~B}_{y}\right) \mathrm{O}_{3}$ perovskites [10-13], several strontium and copper-doped $\mathrm{LaFeO}_{3}$ powders were investigated by photo-electrochemical measurements in order to study their electronic features. The work presented here concerns also their physico-chemical characterization.

\section{Experimental}

\subsection{Synthesis of materials and characterization}

$\mathrm{LaFeO}_{3}$ (LF), $\mathrm{La}_{0.8} \mathrm{Sr}_{0.2} \mathrm{FeO}_{3-w}$ (LSF20), $\mathrm{La}_{0.8} \mathrm{Sr}_{0.2} \mathrm{Fe}_{0.9} \mathrm{Cu}_{0.1} \mathrm{O}_{3-w}$ (LSFC2010) and $\mathrm{La}_{0.8} \mathrm{Sr}_{0.2} \mathrm{Fe}_{0.8} \mathrm{Cu}_{0.2} \mathrm{O}_{3-w}$ (LSFC2020) powders were prepared by citrate auto-combustion of dry gel obtained from a solution of the corresponding nitrates in citric acid solution. Analytical grade $\mathrm{La}_{2} \mathrm{O}_{3}, \mathrm{Sr}\left(\mathrm{NO}_{3}\right)_{2}, \mathrm{Fe}\left(\mathrm{NO}_{3}\right)_{3} \cdot 9 \mathrm{H}_{2} \mathrm{O}, \mathrm{Cu}\left(\mathrm{NO}_{3}\right)_{2} \cdot 2.5 \mathrm{H}_{2} \mathrm{O}$, citric 
acid, nitric acid, and aqueous $\mathrm{NH}_{3}$ were used as the starting materials. A specific amount of dried $\mathrm{La}_{2} \mathrm{O}_{3}$ was dissolved in a nitric acid solution to prepare $\mathrm{La}\left(\mathrm{NO}_{3}\right)_{3} \cdot 6 \mathrm{H}_{2} \mathrm{O}$. The experimental details have been previously reported $[10,11]$. The resulting lightweight powder was calcined at $600-980^{\circ} \mathrm{C}$ for $3 \mathrm{~h}$ in air.

Powder X-ray diffraction patterns (XRD) were collected at room temperature ( $\mathrm{Cu}-\mathrm{K} \alpha$ radiation). The structural refinements were carried out with the Rietveld method of profile analysis for LSF20, LSFC2010 and LSFC2020 calcined at $600^{\circ} \mathrm{C}$. The morphology of the particles was observed at $20,000 \times$ magnification by analytical environmental scanning electron microscopy (LEO $1450 \mathrm{EP}$ ) at $15 \mathrm{kV}$. The BET surface area was obtained by nitrogen adsorption-desorption isotherms according to the conventional BET method using a Micromeritics ASAP 2010 system. Powder samples of the photocatalysts were characterized by ultraviolet-visible diffuse reflectance spectroscopy (UV-vis DRS). The spectra were recorded in air with a spectrophotometer UV/VIS/NIR Jasco V-570 equipped with an integrating sphere for solid samples (model ISN470 ) in the region $200-2000 \mathrm{~nm}, \mathrm{BaSO}_{4}$ was used as reference for the baseline. The reflectance spectra were represented by using the Kubelka-Munk function $F\left(R_{\infty}\right)$ which is proportional to the absorption coefficient obtained for weakly absorbing sample.

\subsection{Electrochemical measurements}

Photocurrent measurements were performed to evaluate the functional characteristics of the samples. To measure dark and illuminated currents chrono-amperometric tests were carried out at room temperature under front wall illumination using an Autolab PGSTAT30 potentiostat/galvanostat in a standard three-electrode set-up with a saturated $\mathrm{Ag} / \mathrm{AgCl}$ reference electrode, a Pt wire as counter and a Ti foil, on which the powder of the samples was deposited, as working electrode. A suspension of ferrite powder, solvent and Carbowax polymer was drop deposited on the Ti foil, dried at $80^{\circ} \mathrm{C}$, and then annealed at $200^{\circ} \mathrm{C}$ in air for $3 \mathrm{~h}$ to remove the Carbowax polymer from the photoelectrode surface. Sunlight was simulated with a $300 \mathrm{~W}$ xenon ozone-free arc-lamp equipped with AM $1.5 \mathrm{G}$ filter at $100 \mathrm{~mW} / \mathrm{cm}^{2}$. Potentiodynamic curves (photo- and dark currents) were obtained under potential scan in the range -1.5 to $+1.5 \mathrm{~V}$ at a rate of $0.015 \mathrm{~V} / \mathrm{s}$ for $\mathrm{LF}$ and LSFC2010 samples. For all the samples potentiostatic plots were obtained by applying a positive bias of $0.1 \mathrm{~V}$ between the photo(working)-electrode and the reference electrode through different $\mathrm{ON}-\mathrm{OFF}$ irradiation cycles. The selected bias conditions are the same generally used to test the photoelectrochemical properties of photoactive materials such as Degussa P25 titania. $1 \mathrm{M} \mathrm{KOH}$ solution purged with $\mathrm{N}_{2}$ was used as the electrolyte.

Quasi-Fermi levels of electrons were measured according to the literature [14]. $20 \mathrm{mg}$ of the powder were suspended in $100 \mathrm{~cm}^{3}$ of $0.1 \mathrm{M} \mathrm{NaNO}_{3}$ in the presence of $20 \mathrm{mg}$ of methyl viologen dichloride and irradiated with UV light (medium-pressure Hg lamp Helios Italquartz, Italy). Suspensions were stirred and purged with $\mathrm{N}_{2}$ prior to and during the measurement. The $\mathrm{pH}$ was adjusted by $\mathrm{HNO}_{3}$ and $\mathrm{NaOH}$ solutions and monitored with a $\mathrm{pH}$-meter. In general the starting suspension had $\mathrm{pH} 1.7$ and the experiment was carried out at room temperature. A large surface platinum flag $\left(5 \mathrm{~cm}^{2}\right)$ and $\mathrm{Ag} / \mathrm{AgCl}$ were working and reference electrodes, respectively. Stable photovoltages were recorded about $1.5 \mathrm{~min}$ after adjusting the $\mathrm{pH}$ value.

\section{Results and discussion}

LF exhibited the orthorhombic symmetry (space group Pnma) and crystallized with the well known orthorhombic perovskite structure in agreement with results previously reported for powders prepared at $600^{\circ} \mathrm{C}[10]$, and at $900^{\circ} \mathrm{C}$ [15]. LSF20 and

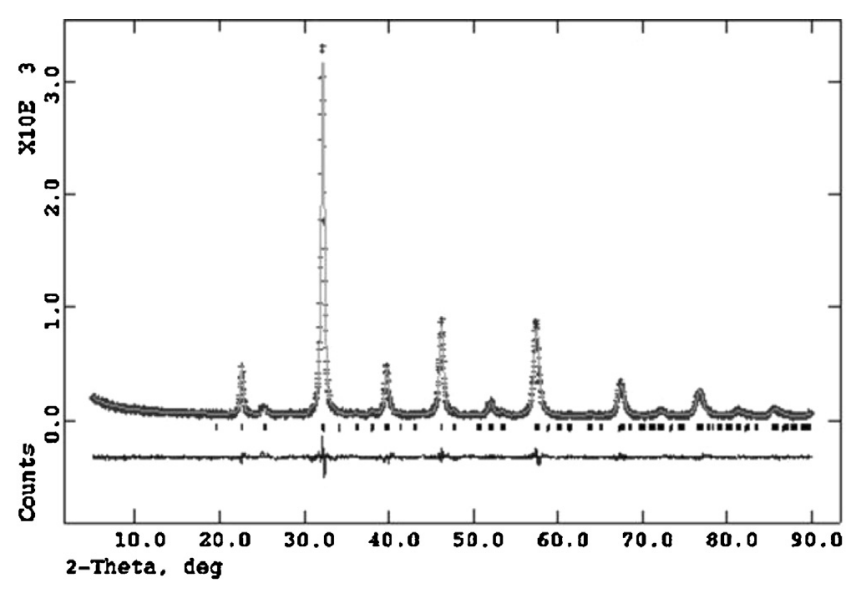

Fig. 1. Observed (cross) and calculated (continuous line) intensities in the XRD pattern of LSFC2010 prepared at $600^{\circ} \mathrm{C}$. The differences between observed and calculated intensities are plotted at the bottom. The crystal structure was refined in the Pnma space group.

LSFC2010 perovskites prepared at $600^{\circ} \mathrm{C}$ were single phase, and crystallized in the orthorhombic symmetry (in Fig. 1 the XRD data from LSFC2010 are shown). For LSFC2020 sample prepared at $600{ }^{\circ} \mathrm{C}$ the reflections were broader and with lower intensity than those of LSFC2010, but no additional peaks were detected in the diffractogram. We have previously reported the structural characterization of samples calcined at $980^{\circ} \mathrm{C}[11,13]$ : LSF20 and LSFC2010 powders were monophasic with orthorhombic symmetry, while LSFC2020 was biphasic, with a main (78.5 wt\%) orthorhombic phase and a secondary rhombohedral phase. The oxygen content determined by Rietveld refinement of neutron diffraction data resulted in full occupancy of the oxygen sites for both LSFC2010 and LSFC2020 [11]. The unit cell volume decreases with increasing $\mathrm{Cu}$ doping. Since the larger $\mathrm{Cu}^{2+}$ cation partially substitutes $\mathrm{Fe}^{3+}$ cation $\left(\mathrm{Cu}^{2+}(\mathrm{VI})=0.73 \AA, \mathrm{Fe}^{3+}(\mathrm{VI})=0.645 \AA\right)$, a charge compensation mechanism occurs by oxidation of $\mathrm{Fe} / \mathrm{Cu}$ cations [13].

The morphology of the LF powder is shown in Fig. 2. Agglomerations of particles with particle size smaller than $100 \mathrm{~nm}$ are detectable. As reported in Table 1 the partial replacement of lanthanum with strontium and of iron with copper in the system $\mathrm{La}_{1-x} \mathrm{Sr}_{x} \mathrm{Fe}_{1-y} \mathrm{Cu}_{y} \mathrm{O}_{3}$ brought a significant increase in the surface area of the samples measured after annealing at $600^{\circ} \mathrm{C}$. In fact an increase from 14 to $25 \mathrm{~m}^{2} / \mathrm{g}$ was observed going from the parent structure of the LF to that of the more substituted LSFC2020.

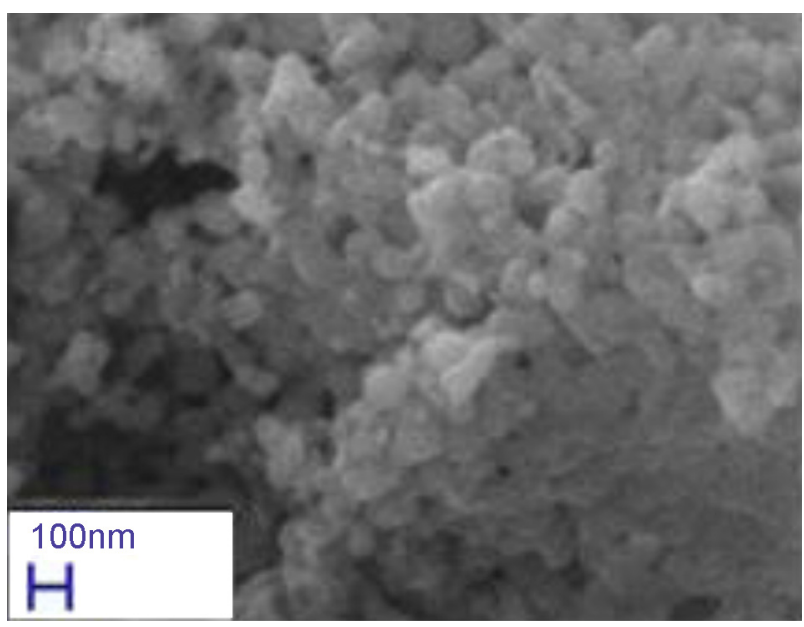

Fig. 2. ESEM micrograph of LF powder calcined at $600^{\circ} \mathrm{C}$. 
Table 1

Selected morphological parameters: powder colour, mean crystallite sizes (from XRD data), and BET surface areas for samples calcined at $600{ }^{\circ} \mathrm{C}$.

\begin{tabular}{|c|c|c|c|c|}
\hline Samples & $\mathrm{LF}^{\mathrm{a}}$ & LSF20 & LSFC2010 & LSFC2020 \\
\hline Colour & Ochre & Black & Black & Black \\
\hline Mean crystallite size (nm) & 43 & 26 & 22 & 18 \\
\hline BET surface area $\left(\mathrm{m}^{2} / \mathrm{g}\right)$ & 14 & 18 & 23 & 25 \\
\hline
\end{tabular}

a BET surface area of LF prepared at $900{ }^{\circ} \mathrm{C}$ is $6 \mathrm{~m}^{2} / \mathrm{g}$.

Correspondingly, crystallite size calculated from XRD data using the Debye Scherrer equation decreases as the $\mathrm{Sr} / \mathrm{Cu}$ doping increases.

Fig. 3A shows the diffuse reflectance UV-vis spectrum of sample $\mathrm{LF}$ calcined at $600^{\circ} \mathrm{C}$. The absorption edge between $400-600 \mathrm{~nm}$ was related to the band-gap energy of LF [7]. It was assigned to the transfer of electrons from the valence band (mainly contributed by strongly mixed $e_{g}$ states of Fe $3 d$ and $\mathrm{O} 2 p$ states) to the conduction band ( $t_{2 g}$ states of Fe $3 d$ ).

For estimation of the optical band gap $E_{g}$ Kubelka-Munk function $F\left(R_{\infty}\right)$ of the diffuse reflectance spectra was used instead of the absorption coefficient. As done for $\mathrm{La}_{1-x} \mathrm{Ag}_{x} \mathrm{FeO}_{3}$ [16] and $\mathrm{Bi}\left(\mathrm{Fe}_{1-x} \mathrm{Mn}_{x}\right) \mathrm{O}_{3}$ [17] the absorption data were modeled assuming a direct gap by plotting $\left(F\left(R_{\infty}\right) E\right)^{2}$ as a function of $E$ the energy of incident photons. The intercept on abscissa of the $\left(F\left(R_{\infty}\right) E\right)^{2}$ vs $\mathrm{E}$ gave the value of optical absorption edge energy. Following this procedure the measured $E_{g}$ for nanosized LF is $2.54 \mathrm{eV}$ (Table 2), larger than that value previously found for dense polycrystalline sample $2.1 \mathrm{eV}$ [7] and for porous submicrometric powders $2.4 \mathrm{eV}$ [16], but smaller than $2.64 \mathrm{eV}$ estimated using direct transition for epitaxial thin film of LF [18].

In LSF20, LSFC2010 and LSFC2020 the absorption of visible light is higher than in LF in accordance with their black color (the parent LF is ochre in color) (see Fig. 3B). As has been reported in refs [7-9] hole doping via $\mathrm{Sr}^{2+}$ for $\mathrm{La}^{3+}$ substitution causes changes in the electronic structure introducing hole states at about $1.0 \mathrm{eV}$ above the Fermi energy. It is important to note that even for Sr-content $x=0.40$ (double than here) the hole states do not overlap the top of the valence band retaining the charge-transfer-type behaviour, although with a minor band-gap energy $[8,9]$.

For LSF20, LSFC2010 and LSFC2020 in addition to the absorption edge between 400 and $600 \mathrm{~nm}$ we considered an additional transition found at lower energy (higher wavelength) than the previous transition. Following Refs. $[8,9]$ this transition was attributed to the hole states doped into the band-gap. The energy of the first transition was determined assuming a direct gap and the estimated transition energies are reported in Table 2 for each material. These correspond to $2.2 \mathrm{eV}$ for LSF20, $2.1 \mathrm{eV}$ for LSFC2010, and $2.3 \mathrm{eV}$ for LSFC2020. The substitution of $\mathrm{Sr}^{2+}$ for $\mathrm{La}^{3+}$ causes a red-shifting of the transition in accordance with a recent work [18].

In agreement with Scafetta et al. [18] the transition found at lower energy likely depicts the true band gap transition. The energy value for this transition was estimated about $0.70 \mathrm{eV}$ for LSF20, LSFC2010 and LSFC2020 (see Fig. 3C).

Fig. 4 reports the current density $(J)$ vs potential $(E)$ curves for the samples LF and LSFC2010 recorded in dark condition and under simulated solar irradiation AM $1.5 \mathrm{G}$. In both cases it is clearly shown how the photocurrent density recorded by irradiation (red and green curves) is significantly higher than the dark current (black and dark green curves) with mean increases in photocurrent density of about $0.8 \mathrm{~mA} / \mathrm{cm}^{2}$ for $\mathrm{LF}$ and $2.9 \mathrm{~mA} / \mathrm{cm}^{2}$ for LSFC2010, respectively for potential values $>1 \mathrm{~V}$, whereas values of about some microamperes per $\mathrm{cm}^{2}$ were observed at lower potential (around $0.1 \mathrm{~V}$ ) as discussed below and well illustrated in chronoamperometric plots reported in Figs. 5 and 6. It is worth to note that the plots do not show a proper plateau region. In order to check a possible contribution from the Ti substrate (for example due to the formation of titanium dioxide) a blank experiment was performed using the Ti foil annealed at $200^{\circ} \mathrm{C}$ in air for $3 \mathrm{~h}$, without the pasted ferrite layers. As expected no photocurrent was measured in accordance with the fact that the production of $\mathrm{TiO}_{2}$ by oxidizing the surfaces of $\mathrm{Ti}$ foils requires a thermal treatment in air at temperatures higher than $400^{\circ} \mathrm{C}$ [19]. Further investigations are required to check the effects of the porosity of the ferrite layers on the current density.

As concerns the potentiostatic plots by photo-irradiation with UV-vis light a rapid generation of photocurrent was observed when the electrons photogenerated by the materials were captured and transported on the Ti foil (Fig. 5). All the samples were found to be photoactive and a gradual reduction of the photocurrent was observed when the tests were conducted with the aid of filters capable of blocking increasing ranges of the incident UV radiation (see Fig. 6). The results show that the LF sample calcined at $600^{\circ} \mathrm{C}$ exhibits the highest activity, and the activity decreases with increasing calcination temperature, which is in good agreement with the surface area measurements, indicating lower activity for the samples with smaller surface area. The observed photocurrent response was significantly different depending on the composition of the samples, with a higher density of photocurrent for LF compared to that recorded for the samples with partial substitution of lanthanum and iron in the structure. Furthermore ON/OFF illumination of the materials deposited on the photoelectrode shows an instantaneous rise in photocurrent and quick recovery to the original photocurrent density through multiple ON/OFF cycles. The monitoring during discontinuous illumination revealed stability and reproducibility of the photocurrent density in all the tested samples (see Fig. 7).

Quasi-Fermi levels of electrons, $E_{\mathrm{fb}}$, were measured according to the literature [14] by measuring the photovoltage as a function of $\mathrm{pH}$ value. For this purpose a slurry electrode consisting of $20 \mathrm{mg}$ of the powder, suspended in $100 \mathrm{~cm}^{3}$ of $0.1 \mathrm{M} \mathrm{NaNO}_{3}$ in the presence of $20 \mathrm{mg}$ of methyl viologen dichloride $\left(\mathrm{MV}^{2+}\right.$ ) was irradiated with UV light (medium-pressure Hg lamp Helios Italquartz, Italy). Increasing the $\mathrm{pH}$ value of the suspension shifts the edges of the conduction and valence bands towards more negative potentials so that, approaching the inflection point $\mathrm{pH}_{0}$, photogenerated electrons can reduce $\mathrm{MV}^{2+}$ present into the solution to its corresponding radical cation. A lower $\mathrm{pH}_{0}$ value corresponds to a more negative quasi-Fermi level. From $\mathrm{pH}_{0}$ value of the corresponding

Table 2

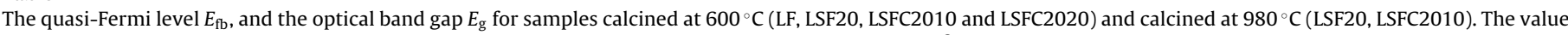
of optical absorption edge energy was obtained by extrapolating to zero a linear fit to a plot of $\left(F\left(R_{\infty}\right) E\right)^{2}$ vs $E$.

\begin{tabular}{|c|c|c|c|c|c|c|}
\hline Samples & $\mathrm{LF} 600^{\circ} \mathrm{C}$ & LSF20 $600^{\circ} \mathrm{C}$ & LSF20 $980^{\circ} \mathrm{C}$ & LSFC2010 $600^{\circ} \mathrm{C}$ & LSFC2010 $980^{\circ} \mathrm{C}$ & LSFC2020 $600^{\circ} \mathrm{C}$ \\
\hline$E_{\mathrm{g}}(\mathrm{eV})$ & 2.54 & 0.7 & - & 0.7 & 0.8 & 0.7 \\
\hline$E_{\mathrm{fb} 1}(\mathrm{~V})$ & -0.63 & -0.62 & -0.63 & -0.65 & -0.67 & -0.63 \\
\hline$E_{\mathrm{fb} 2}(\mathrm{~V})$ & - & - & - & -0.56 & - & -0.56 \\
\hline
\end{tabular}



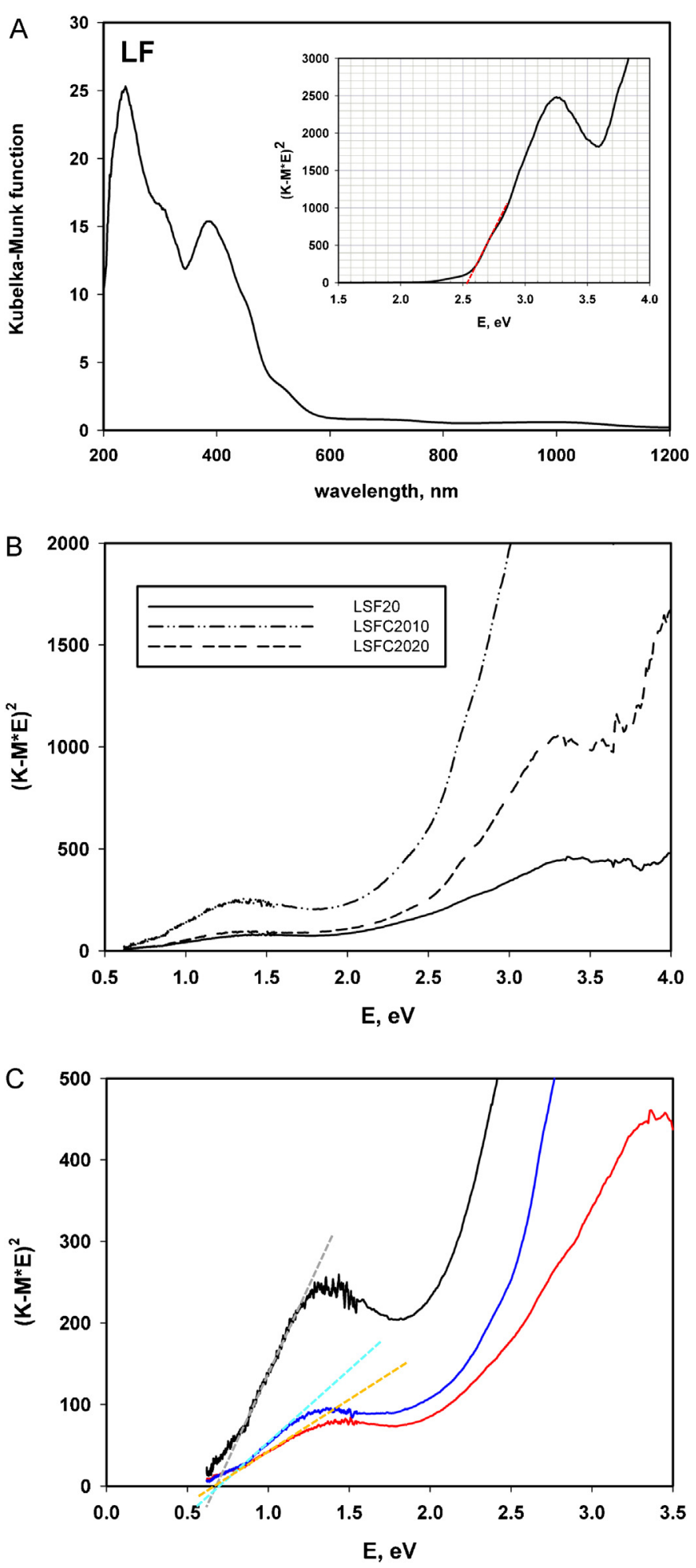

Fig. 3. UV-vis absorption spectra of LF (A) and LSF20, LSFC2010 and LSFC2020 (B and C) calcined at $600^{\circ} \mathrm{C}$.

titration curve (see Fig. 8), the quasi-Fermi level at pH 7 can be calculated via the following equation:

$E_{\mathrm{fb}}(\mathrm{pH})=E^{\circ} \mathrm{MV}^{2+} / \mathrm{MV}^{+}+k\left(\mathrm{pH}_{0}-\mathrm{pH}\right)$

where $E^{\circ} \mathrm{MV}^{2+} / \mathrm{MV}^{+}$is the redox potential of the $\mathrm{MV}^{2+} / \mathrm{MV}^{+}$couple and $k$ is assumed to be equal to $0.059 \mathrm{~V}$. The obtained values are reported in Table 2 .

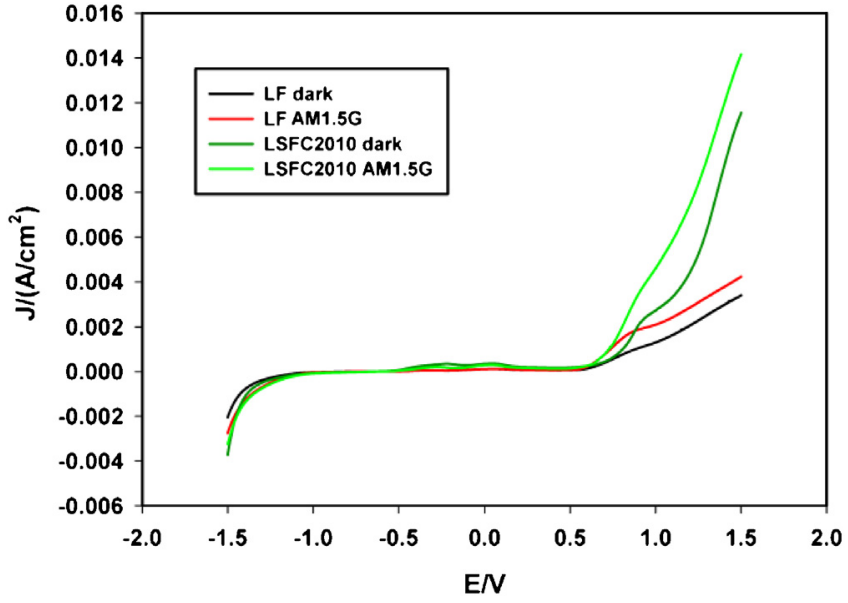

Fig. 4. Potentiodynamic plots (photocurrent density $(J)$ versus applied potential $(E)$ ) of LF and LSFC2010 samples recorded in the dark (black and dark green lines) and under light radiation (red and light green lines) at scan rate $0.015 \mathrm{~V} / \mathrm{s}$. The photoactivity was examined under AM $1.5 \mathrm{G}\left(100 \mathrm{~mW} / \mathrm{cm}^{2}\right)$ simulated solar irradiation in $1 \mathrm{M} \mathrm{KOH}$ electrolyte with a $\mathrm{Pt}$ wire and $\mathrm{Ag} / \mathrm{AgCl}$ as the counter and the reference electrodes, respectively. (For interpretation of the references to colour in this figure legend, the reader is referred to the web version of the article.)

Fig. 8 reports the measurements carried out with the sample LSFC2010 prior to (A1) and after (A2) calcination at $980^{\circ} \mathrm{C}$ and with the sample LSF20 prior to (B1) and after (B2) calcination at $980^{\circ} \mathrm{C}$. Sample LSFC2020 (not shown) showed a titration curve similar to that in Fig. 8A1 whereas samples without copper behave analogously to Fig. 8B1 (not shown).

It should be pointed out that the present method for determining the quasi-Fermi level can be successfully used for both $p$-type and $n$-type semiconductors. In fact, semiconductor irradiation of suitable energy causes the formation of two quasi-Fermi levels (one for the holes and one for the electrons) and the method in both cases gives information about the potentials of the photogenerated electrons. By assuming that the difference between the quasi-Fermi level potential and the conduction band edge is negligible, the valence band edge values are obtained by addition of the band gap energies reported in Table 2.

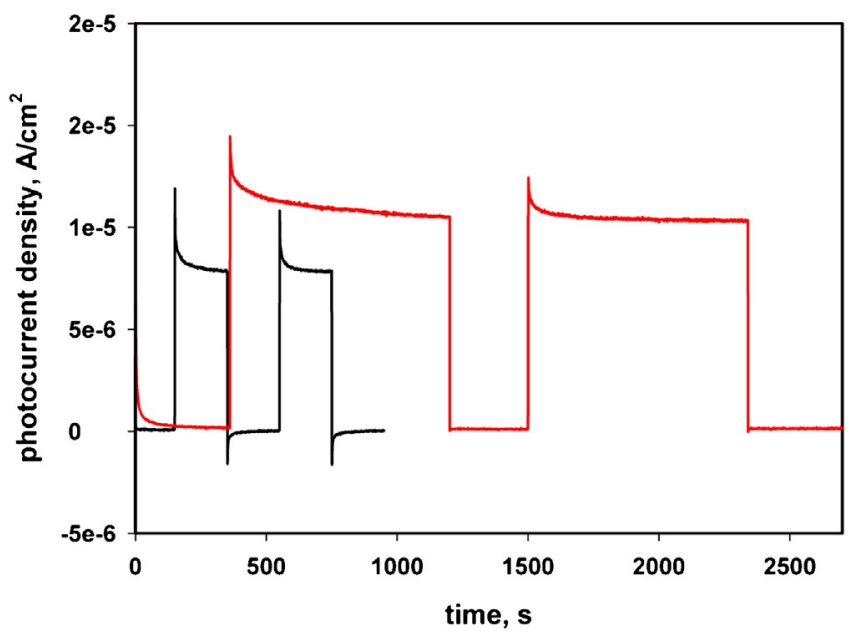

Fig. 5. Photocurrent profiles of LSFC2010 and LF samples; black line and red line, respectively. Both sample were calcined at $600^{\circ} \mathrm{C}$ and deposited on a Ti metal support. The potential of the $\mathrm{KCl}$ saturated $\mathrm{Ag} / \mathrm{AgCl}$ reference electrode was $E^{\circ}=0.197 \mathrm{~V}$ vs SHE at $25^{\circ} \mathrm{C}$. ON-OFF cycles with different interval time for a better visualization of the trends were carried out. Irradiation was conducted by a $300 \mathrm{~W}$ Xe light source. (For interpretation of the references to colour in this figure legend, the reader is referred to the web version of the article.) 


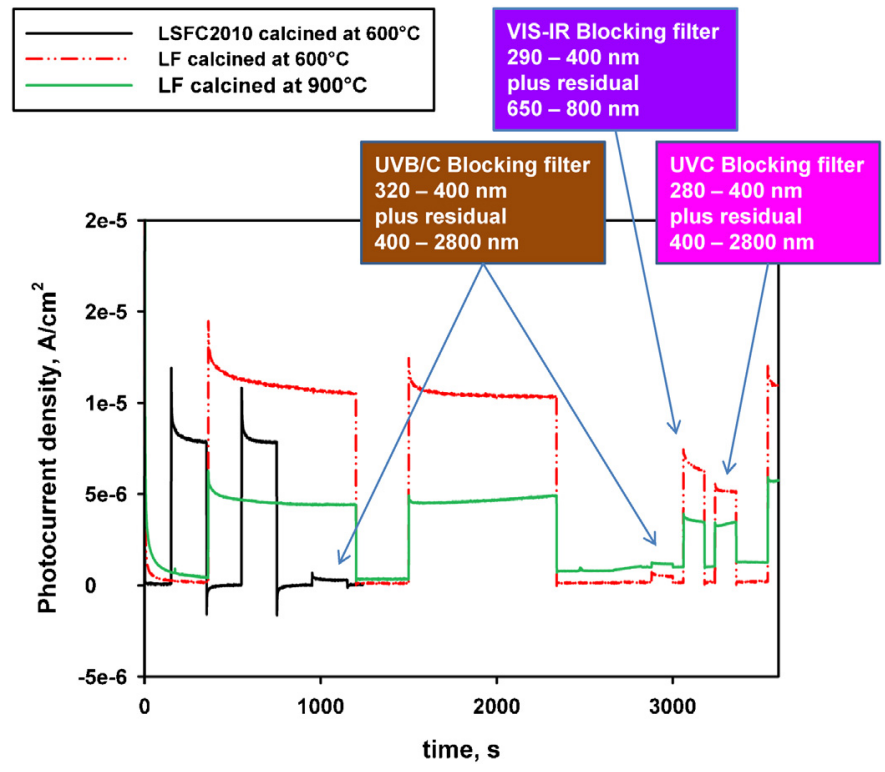

Fig. 6. Typical photocurrent profiles of $\mathrm{LF}$ (calcined at $600^{\circ} \mathrm{C}$ and $900{ }^{\circ} \mathrm{C}$ ), and LSFC2010 (calcined at $600^{\circ} \mathrm{C}$ ) recorded under illumination with a $300 \mathrm{~W}$ Xe light source with (or without) blocking filters used to cut different fractions of incident light. The potential of the $\mathrm{KCl}$ saturated $\mathrm{Ag} / \mathrm{AgCl}$ reference electrode was $E^{\circ}=0.197 \mathrm{~V}$ vs SHE at $25^{\circ} \mathrm{C}$.

It may be noted that the position of the quasi-Fermi level for all the catalysts is about the same within experimental error (between -0.62 and $-0.67 \mathrm{~V}$ ). The presence of strontium did not influence the flat band potential of the powders. On the other hand, the

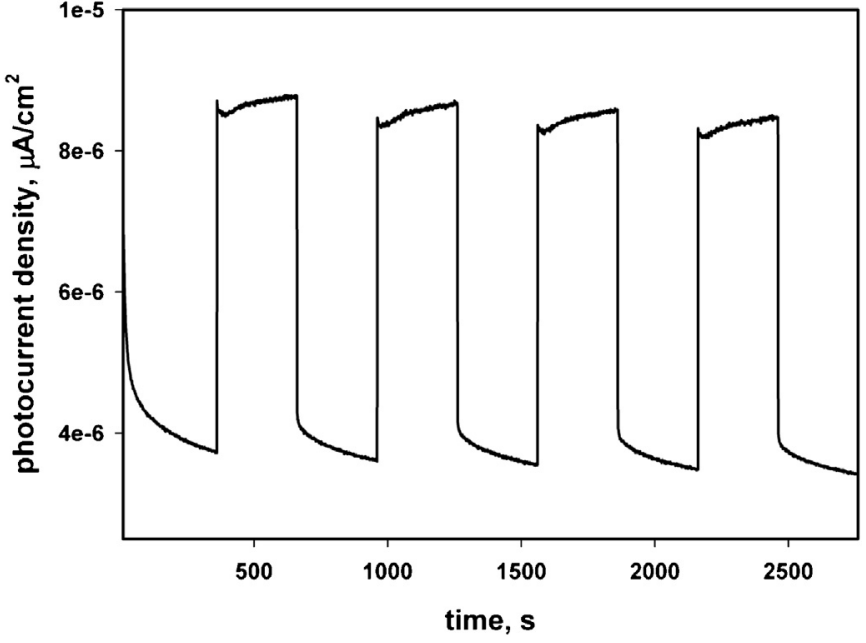

Fig. 7. Typical photocurrent response of a LF film (activated at $900^{\circ} \mathrm{C}$ and deposited on Ti metal support) to ON-OFF cycles carried out by means of a $300 \mathrm{~W}$ Xe light source. The potential of the $\mathrm{KCl}$ saturated $\mathrm{Ag} / \mathrm{AgCl}$ reference electrode was $E^{\circ}=0.197 \mathrm{~V}$ vs SHE at $25^{\circ} \mathrm{C}$.

presence of copper caused an important and reproducible change in the titration curve as shown in Fig. 8. In fact, at about $\mathrm{pH} 4.5$ the curve slope suddenly changes indicating that, from this $\mathrm{pH}$ value, an electron transfer can take place from a different phase or a different semiconducting material present into the powder to the $\mathrm{MV}^{2+}$ dissolved into the suspension. This feature was observed only when copper was present into the powders i.e. for LSFC2010 and for LSFC2020. Rusina et al. [20] observed a similar behaviour
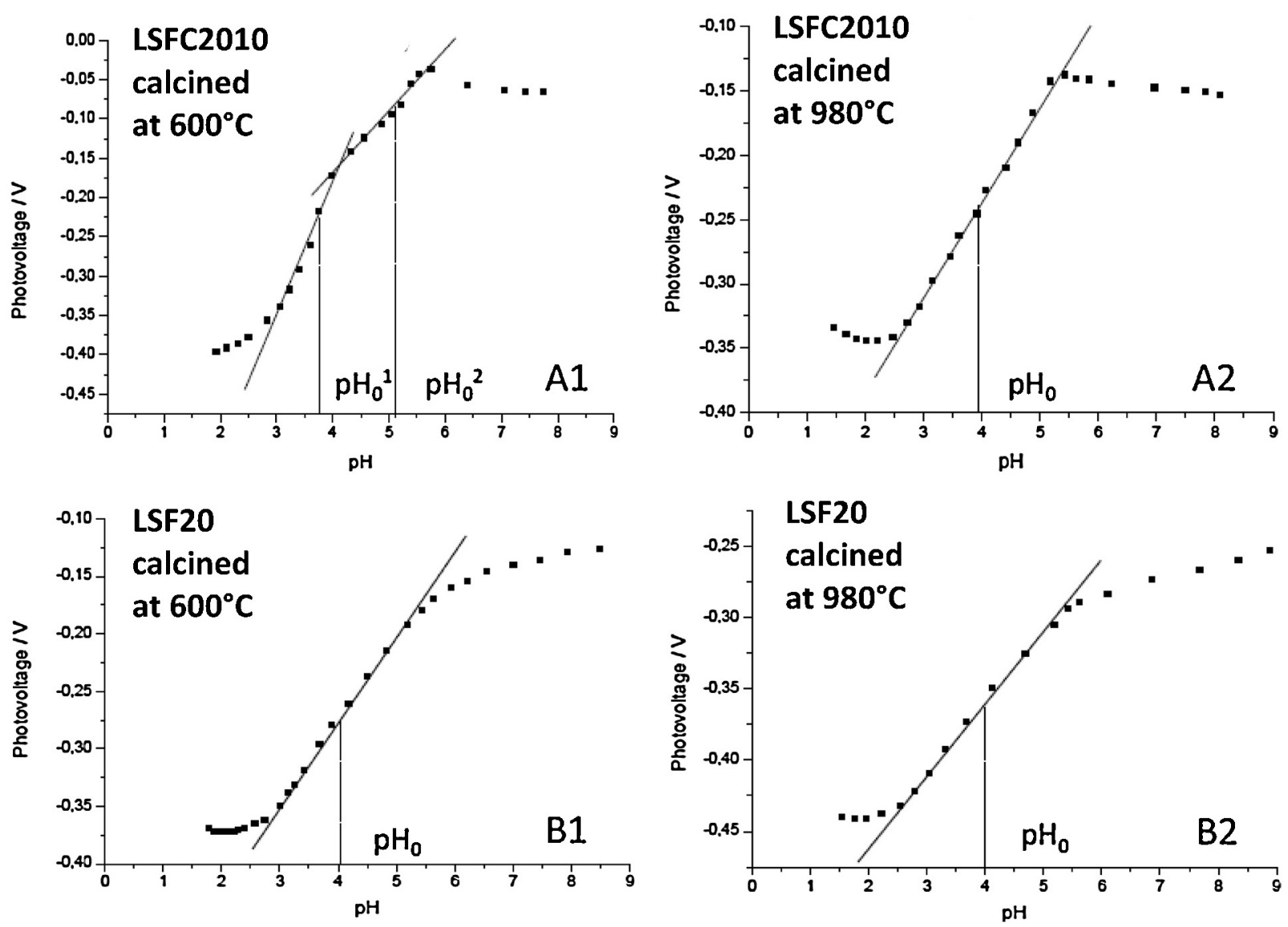

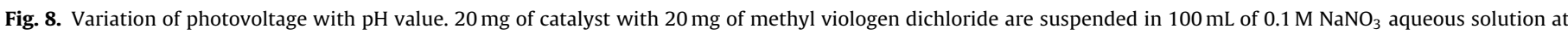
room temperature. Pt, working electrode and $\mathrm{Ag} / \mathrm{AgCl}$, reference electrodes. 
for mixed semiconductors titanium dioxide-iron titanate. This finding suggests that $\mathrm{Cu}$-doping promotes the presence into the powders calcined at $600^{\circ} \mathrm{C}$ of a secondary phase with different electronic properties. Although the XRD analysis did not suggest the presence of a secondary phase for LSFC2010 and LSFC2020 powders calcined at $600^{\circ} \mathrm{C}$ the Rietveld refinements gave unsatisfactory agreement factors, so a certain structural disorder and/or lack of homogeneousness could not be excluded. Moreover, the calcination at $980^{\circ} \mathrm{C}$ of the $\mathrm{Cu}$-containing samples resulted in the disappearance of this specific feature, leaving a powder with the same flat band potential as the others listed in Table 2. Interestingly, calcining at the same temperature the Cu-undoped samples (LF and LSF20) did not produce changes in the titration curve. For samples calcined at $980^{\circ} \mathrm{C}$ detailed NPD analyses [11] have shown that LSFC2010 is monophasic, while LSFC2020 is largely biphasic, so it is unlikely that the change in the titration curve is due to the disappearance of a secondary phase after calcining at $980^{\circ} \mathrm{C}$. It has been reported that in the system $\mathrm{La}_{1-x} \mathrm{Sr}_{x} \mathrm{FeO}_{3-w}$ the higher the calcining temperature the lower are the concentration of oxygen vacancy and the content of iron cations with oxidation state larger than +3 [21]. Accordingly, the NPD analysis has indicated a full occupancy of the oxygen sites in LSFC2010 and LSFC2020 calcined at $980^{\circ} \mathrm{C}$ [11]. Possibly the thermal treatment at $980^{\circ} \mathrm{C}$ causes a good bulk and surface chemical homogeneousness in $\mathrm{Cu}-$ containing samples. In general, doping with copper may lower the temperature during the auto-combustion synthesis, as found for the system $\mathrm{LaFe}_{1-y} \mathrm{Cu}_{y} \mathrm{O}_{3-w}$ [10]. However further investigations are necessary to clarify this point.

The extent of photocurrent obtained in the case of Cu-doped powders was lower with regard to that obtained by using copperfree powders. This finding is in good agreement with the results of the quasi-Fermi level measurements, i.e. with the presence of intermediate energy states introduced when $\mathrm{Cu}$ was present in the powders. Being these states at lower energy than the primary Fermi level of the powders, recombination of the photoproduced excitons and lowering of the photocurrent response are more likely.

\section{Conclusions}

All samples showed moderate absorbance of visible light. All powders showed photocurrent response; the highest photocurrent was obtained for LF calcined at $600^{\circ} \mathrm{C}$.

In order to elucidate the complex electronic properties of these samples, the quasi-Fermi levels of electrons were measured and the results indicate that: (i) the position of the quasi-Fermi level for all the photocatalysts calcined in the range $600-980^{\circ} \mathrm{C}$ is about the same within experimental error (between -0.62 and $-0.67 \mathrm{~V}$ ), (ii) doping with strontium does not influence the flat band potential of the powders, and (iii) for LSFC2010 and LSFC2020 the presence of copper caused an important and reproducible change in the titration curve, indicating the presence of intermediate energy states in the samples calcined at $600^{\circ} \mathrm{C}$, but not in those calcined at $980^{\circ} \mathrm{C}$. Further work will be required to ascertain whether an intermediate temperature structural transition takes place, and to investigate a possible photocatalytic activity for removal of organic molecules present in air or water effluents. Based on these photoelectrochemical characteristics, the proposed perovskite-type lanthanum powders could be considered not only as traditional electrodes for high temperature solid oxide fuel cells (SOFC) but also as functional inorganic materials in photocatalytic applications operating at low temperature.

\section{Acknowledgements}

The initial part of the work has been financially supported by INSTM and Regione Lombardia within the frame of the project "Nanostructured catalysts for energy and environment". Thanks to Ivan Grigioni for technical assistance.

\section{References}

[1] T. Ohno, T. Tsubota, Y. Nakamura, K. Sayama, Preparation of S, C cation-codoped $\mathrm{SrTiO}_{3}$ and its photocatalytic activity under visible light, Applied Catalysis A: General 288 (2005) 74.

[2] V. Augugliaro, M. Litter, L. Palmisano, J. Soria, The combination of heterogeneous photocatalysis with chemical and physical operations: a tool for improving the photoprocess performance, Journal of Photochemistry and Photobiology C: Photochemistry Reviews 7 (2006) 127.

[3] D.F. Wang, T. Kako, J.H. Ye, Efficient photocatalytic decomposition of acetaldehyde over a solid-solution perovskite $\left(\mathrm{Ag}_{0.75} \mathrm{Sr}_{0.25}\right)\left(\mathrm{Nb}_{0.75} \mathrm{Ti}_{0.25}\right) \mathrm{O}_{3}$ under visible-light irradiation, Journal of the American Chemical Society 130 (2008) 2724.

[4] H. Su, L. Jing, K. Shi, C. Yao, H. Fu, Synthesis of large surface area $\mathrm{LaFeO}_{3}$ nanoparticles by SBA- 16 template method as high active visible photocatalysts, Journal of Nanoparticle Research 12 (2010) 967.

[5] G. Centi, S. Perathoner, Problems and perspectives in nanostructured carbonbased electrodes for clean and sustainable energy, Catalysis Today 150 (2010) 151.

[6] I. Wærnhus, P.E. Vullum, R. Holmestad, T. Grande, K. Wiik, Electronic properties of polycrystalline $\mathrm{LaFeO}_{3}$. Part I: experimental results and the qualitative role of Schottky defects, Solid State Ionics 176 (2005) 2783.

[7] T. Arima, Y. Tokura, J.B. Torrence, Variation of optical gaps in perovskite-type 3d transition-metal oxides, Physical Review B 48 (1993) 17006.

[8] A. Chainani, M. Mathew, D.D. Sarma, Electronic structure of $\mathrm{La}_{1-x} \mathrm{Sr}_{x} \mathrm{FeO}_{3}$, Physical Review B 48 (1993) 14818.

[9] H. Wadati, D. Kobayashi, H. Kumigashira, K. Okazaki, T. Mizokawa, A. Fujimori, K. Horiba, M. Oshima, N. Hamada, M. Lippmaa, M. Kawasaki, H. Koinuma, Holedoping-induced changes in the electronic structure of $\mathrm{La}_{1-x} \mathrm{~S}_{x} \mathrm{FeO}_{3}$ : soft X-ray photoemission and absorption study of epitaxial thin films, Physical Review B 71 (2005) 035108.

[10] T. Caronna, F. Fontana, I. Natali Sora, R. Pelosato, Chemical synthesis and structural characterization of the substitution compound $\mathrm{LaFe}_{1-x} \mathrm{Cu}_{x} \mathrm{O}_{3}$ $(x=0-0.40)$, Materials Chemistry and Physics 116 (2009) 645.

[11] I. Natali Sora, T. Caronna, F. Fontana, C. De Julián Fernández, A. Caneschi, M. Green, Crystal structures and magnetic properties of strontium and copper doped lanthanum ferrites, Journal of Solid State Chemistry 191 (2012) 33.

[12] A. Cavalieri, T. Caronna, I. Natali Sora, J.M. Tulliani, Electrical characterization of room temperature humidity sensors in $\mathrm{La}_{0.8} \mathrm{Sr}_{0.2} \mathrm{Fe}_{1-x} \mathrm{Cu}_{x} \mathrm{O}_{3}(x=0,0.05,0.10)$, Ceramics International 38 (2012) 2865.

[13] I. Natali Sora, T. Caronna, F. Fontana, C. de Julián Fernández, A. Caneschi, M. Green, P. Bonville, Charge compensation and magnetic properties in $\mathrm{Sr}$ and $\mathrm{Cu}$ doped La-Fe perovskites, EPJ Web of Conferences 40 (2013) 15005.

[14] A.M. Roy, G.C. De, N. Sasmal, S.S. Bhattacharyya, Determination of the flat-band potential of semiconductor particles in suspension by photovoltage measurement, International Journal of Hydrogen Energy 20 (1995) 627.

[15] H. Falcon, A.E. Goeta, G. Punte, R.E. Carbonio, Crystal structure refinement and stability of $\mathrm{LaFe}_{\chi} \mathrm{Ni}_{1-\chi} \mathrm{O}_{3}$ solid solutions, Journal of Solid State Chemistry 133 (1997) 379.

[16] M.B. Bellakki, B.J. Kelly, V. Manivannan, Synthesis, characterization, and property studies of $(\mathrm{La}, \mathrm{Ag}) \mathrm{FeO}_{3}(0.0 \leq x \leq 0.3)$, Journal of Alloys and Compounds 489 (2010) 64.

[17] X.S. Xu, J.F. Ihlefeld, J.H. Lee, O.K. Ezekoye, E. Vlahos, R. Ramesh, V. Gopalan, X.Q. Pan, D.G. Schlom, J.L. Musfeldt, Tunable band gap in $\mathrm{Bi}\left(\mathrm{Fe}_{1-x} \mathrm{Mn}_{x}\right) \mathrm{O}_{3}$ films, Applied Physics Letters 96 (2010) 192901

[18] M.D. Scafetta, Y.J. Xie, M. Torres, J.E. Spanier, S.J. May, Optical absorption in epitaxial $\mathrm{La}_{1-\chi} \mathrm{Sr}_{x} \mathrm{FeO}_{3}$ thin films, Applied Physics Letters 102 (2013) 081904.

[19] L. Özcan, S. Yurdakal, V. Augugliaro, V. Loddo, S. Palmas, G. Palmisano, L. Palmisano, Photoelectrocatalytic selective oxidation of 4-methoxybenzyl alcohol in water by $\mathrm{TiO}_{2}$ supported on titanium anodes, Applied Catalysis B: Environmental 132-133 (2013) 535.

[20] O. Rusina, W. Macyk, H. Kisch, Photoelectrochemical properties of a dinitrogenfixing iron titanate thin film, Journal of Physical Chemistry B 109 (2005) 10858.

[21] A. Wattiaux, J.C. Grenier, M. Pouchard, P. Hagenmuller, Electrolytic oxygen evolution in alkaline-medium on $\mathrm{La}_{1-x} \mathrm{Sr}_{x} \mathrm{FeO}_{3-y}$ perovskite-related ferrites. II: Influence of bulk properties, Journal of The Electrochemical Society 134 (1987) 1718. 